\title{
PRAGMÁTICA DE UMA METÁFORA: A CIDADE FERIDA DE ARQUÍLOCO A PÍNDARO
}

\begin{abstract}
Agatha Bacelar*
RESUMO: Este trabalho passa em revista as ocorrências da imagem da cidade ferida na poesia grega de Arquíloco a Píndaro. Após observar essa figura nos versos de Sólon, volta-se para algumas questões de método acerca da análise de metáforas em uma língua antiga; em seguida, a noção de corpo cívico se torna objeto de uma breve digressão; enfim, procedese à leitura de passagens de Arquíloco, dos Theognidea e de Píndaro, no intuito de observar as dinâmicas pragmáticas da figura da cidade ferida.
\end{abstract}

PALAVRAS-CHAVE: ferida; metáfora, sôma; "corpo cívico"; autoridade da poesia.

\section{PRAGMATIQUE D'UNE MÉTAPHORE: LA CITÉ BLESSÉE D'ARCHILOQUE À PINDARE}

RÉSUMÉ: Ce travail passe en revue les occurrences de l'image de la cité blessée dans la poésie grecque d'Archiloque à Pindare. Après regarder cette figure dans des vers de Solon, on se tourne vers quelques questions de méthode sur l'analyse des métaphores dans une langue ancienne; ensuite, la notion de corps civique fait l'objet d'une petite digression; enfin, on lit quelques passages d'Archiloque, des Theognidea et de Pindare en vue de dégager les enjeux pragmatiques de la figure de la cité blessée.

MOTS-CLÉS: blessure; métaphore; sôma; "corps civique"; autorité de la poésie.

\section{A} cidade doente é uma tópica bem difundida na Grécia da época clássica, não apenas na poesia trágica mas também na historiografia, na filosofia e na oratória. ${ }^{1}$ Mas antes que esta figura circule nos usos linguageiros gregos do séc V a.C, os distúrbios da cidade foram designados por meio da imagem de uma ferida. $\mathrm{O}$ objetivo do presente texto é passar em revista as principais passagens em que ocorre a imagem da cidade ferida na poesia grega arcaica, de Arquíloco a Píndaro. Começarei observando esta figura nos versos

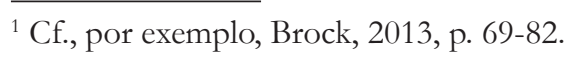

* Departamento de Português, Linguística e Línguas Clássicas da Universidade de Brasília. agathabacelar@unb.br 
de Sólon; em um segundo momento, irei me voltar para algumas questões de método em torno da análise de enunciados metafóricos em uma língua morta; em seguida, é a noção de "corpo cívico", em geral considerada a base da imagem da cidade sofrente, que será objeto de uma pequena digressão; enfim, voltarei às ocorrências da metáfora da cidade ferida em passagens de Arquíloco, dos Theognidea e de Píndaro para tentar mostrar as implicações pragmáticas desta metáfora.

\section{A Eunomia de Sólon} ordem": ${ }^{2}$

Vejamos, então, os versos da elegia de Sólon conhecida pelo título Eunomía, "Boa

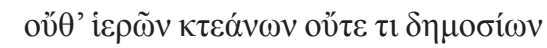

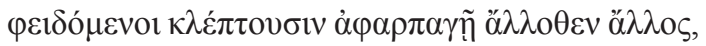

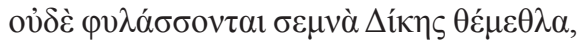

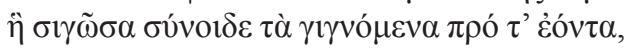

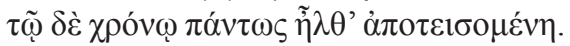

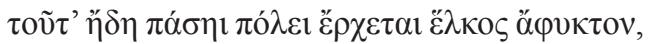

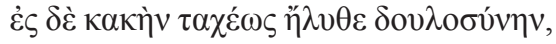

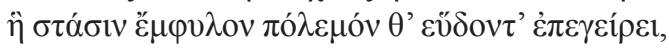

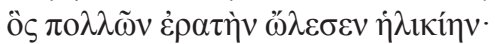

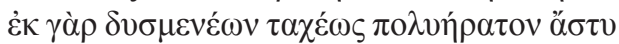

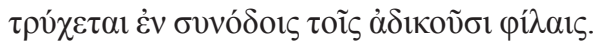

sem respeitar nem os bens sagrados, nem os do povo, roubam, saqueando cada um de seu lado, e não cuidam da augusta sede da Justiça [Dikè] que, em silêncio, testemunha o que se passa e o que se passou e com o tempo vem infalivelmente exigir recompensa. Eis a ferida [hélkos] inevitável que ora chega a toda a cidade e que, rápido, leva à maléfica escravidão, que desperta a dissensão intestina e a guerra adormecida, que faz perecer a juventude amada por muitos; pois, por causa dos inimigos, a cidade muito amada, rápido, se consome nos complôs caros aos injustos.

Os versos 15 a 17 deste poema de Sólon frequentemente trazem à mente a descrição da cidade injusta dada por Hesíodo em Os trabalhos e os dias (Hes. Erga, 213-249). Os paralelismos entre os dois poemas foram evidenciados por diversos helenistas: ${ }^{3}$ nos dois casos, males físicos acusam a falta de respeito à justiça, Dikèe, personificada - peste e fome

\footnotetext{
${ }^{2}$ Solon fr. 3 Gentili-Prato (= 4 West), 12-22. Salvo menção contrária, todas as traduções são de minha responsabilidade.

${ }^{3}$ Para uma análise detalhada das relações entre o fr. 3 Gentili-Prato de Sólon e a poesia hesiódica, ver Irwin, 2005, p. 155-198.
} 
em Hesíodo (limòn homoû kai loimón, Erga, 243) e ferida em Sólon. Para meus propósitos aqui, são as diferenças entre os dois poemas que merecem atenção. Primeiro, em Os trabalhos e os dias, a personificação da justiça se dá através de sua caracterização como vítima que chora (klaíousa, 222) e é Zeus quem, do alto do Olimpo, faz recair a peste sobre as cidades onde imperam as injustiças. De outro lado, no poema de Sólon, detendo um saber sobre o passado e o futuro semelhante àquele das Musas e dos profetas, ${ }^{4}$ a justiça tem, ela mesma, o poder de se vingar, manifestando-se de forma silenciosa e infalível - o que lembra a inexorabilidade das doenças espontâneas e igualmente silenciosas que saem da jarra aberta por Pandora em Os trabalhos e os dias (102-104). Se a justiça de Sólon não precisa de Zeus é porque em seu poema a questão é apresentada como coisa humana: a elegia se inicia justamente com a seguinte afirmação: "Nossa cidade jamais perecerá conforme um quinhão de Zeus/ nem por desígnios de aventurados deuses imortais". ${ }^{5}$ O que não nos autoriza a ver nos versos do legislador ateniense os resultados de um suposto processo de laicização da justiça, como demonstra o caráter sagrado de sua sede (semná, "augusta", 14) e o papel do próprio Zeus em outro fragmento do poeta. ${ }^{6}$ A ferida de que sofre a cidade é causada exclusivamente pelo comportamento dos mortais aos quais o poema se dirige, de modo que não seja possível a ninguém evocar a arbitrariedade que por vezes caracteriza a justiça de Zeus, ao fazer os descendentes pagarem transgressões cometidas por seus ancestrais. ${ }^{7}$

Além disso, e de modo mais significativo, a peste, loimós, enviada por Zeus às cidades tem uma referência concreta e bem precisa, é o próprio Hesíodo que a descreve (os homens morrem, as mulheres não engravidam e as casas se enfraquecem, cf. 243-244). Já a ferida, bélkos, a forma assumida pela retribuição da justiça no poema de Sólon, tem um sentido que se qualifica como figurado. Resposta aos atos injustos, a ferida é o estopim de uma série de males que se seguem em um encadeamento causal (18-20): a escravidão desperta a dissensão civil e a guerra, e esta, por sua vez, traz a morte dos jovens amados por muitos. ${ }^{8} \mathrm{~A}$ ferida é

${ }^{4}$ Cf., p. ex., Hes. Theog. 38, em que as musas, filhas de Zeus e de Mnemosyne, "dizem as coisas que

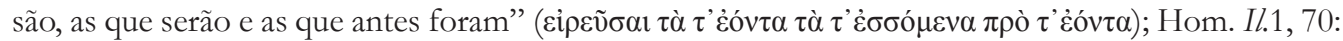

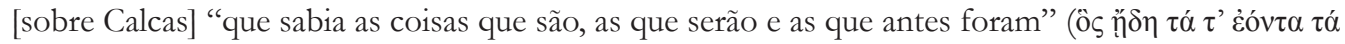

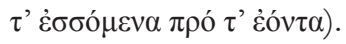

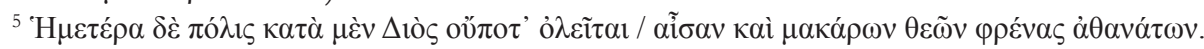

${ }^{6}$ Cf. Sol. fr. 1 Gentili-Prato (= 13 West) com os comentários de Irwin, 2005, p. 175-180.

${ }^{7}$ Cf. Sol. fr. 1 Gentili-Prato, 25-32.

${ }^{8} \mathrm{Ou}$, seguindo a interpretação sintática dos versos $18-19$ proposta por Jaeger (1998, p. 520, n. 27) e adotada por Noussia (2001, p. 250) - interpretação essa que toma como referente do pronome relativo (he "que" no feminino, 18) não seu antecedente imediato, doulosínè ("escravidão"), mas pásei pólei ("toda a cidade", 17), e que considera o verso 18 uma paratática com valor consecutivo: seria, nesse caso, a cidade ferida quem desperta a dissensão e a guerra, e a escravidão consequência dessa última. Mas é possível que, atribuindo-se a referência do relativo à doulosýné a inversão entre causa e consequência nas relações entre a escravidão e a guerra seja um efeito para destacar o sentido figurado dessa escravidão (cf. Irwin, 2005, p. 98). Independentemente da leitura adotada, o sentido de doulosýné permanece vago - podendo remeter simultaneamente à escravidão de fato, aos hek.témoroi (camponeses que haviam se tornado escravos por endividamento e foram libertados por decreto de 
uma metáfora das consequências trazidas pela falta de respeito à justiça. Certamente, atrelada à personificação de Dikè, a metáfora da ferida pertence à imagética da guerra: a punição das injustiças assume a forma de um contra-ataque. Mas o recurso à noção de ferida inaugura, ao menos para nós, dado estado atual da transmissão dos textos gregos, a tópica da cidade sofrente na Grécia antiga.

\section{METÁfora: Questões de MÉTOdo}

Talvez tão inevitável quanto a retribuição da justiça em Sólon, a problemática da constituição do sentido figurado em geral, e da metáfora em particular, se impõe a nós, leitores da Eunomía. Geoffrey Lloyd destacou que a emergência do conceito de metáfora na filosofia de Aristóteles se insere em uma polêmica que visa a descreditar os discursos rivais e que a distinção entre sentido figurado e sentido literal só é pertinente quando se torna explícita; já Ruth Padel observa acerca do uso de metáforas nos discursos "fisiológicos" na Grécia antiga: "a imagem não é um veículo da explicação. Ela é a explicação"."

Sem discordar destas observações, parece útil manter, na análise de textos antigos, as distinções que os estudos linguísticos estabelecem entre sentido figurado e condições de verdade. É claro, falar em sentido figurado implica uma diferença de estatuto estre esse último e o sentido considerado literal, mas nada nos obriga a situar esta diferença em termos de uma adequação entre sentido e realidade. A distinção se dá mais em termos de acessibilidade na memória discursiva dos falantes de uma língua, que reconhecem uma orientação analogicamente motivada do sentido mais acessível ao menos acessível. Assim, a distinção não supõe necessariamente um questionamento, muito menos uma negação do caráter explicativo, epistêmico e cognitivo da categoria do figurado. Pelo contrário, as correspondências realizadas por esta motivação analógica nos oferecem uma ferramenta preciosa para tentar compreender as formas de pensar específicas de uma dada cultura.

Bem entendido, este valor operatório só se verifica sob a condição de não projetar sobre as manifestações linguageiras antigas as distinções entre "literal" e "figurado" em vigor nas nossas línguas modernas. Por outro lado, se o sentido figurado se define em termos de acessibilidade na memória discursiva dos falantes de uma língua, e se, como caso específico de sentido figurado, a metáfora se define como um certo desvio de ordem semântica em relação às configurações de sentido tidas por "comuns", é preciso constatar que nossa capacidade de distinguir o literal do figurado em uma língua antiga é extremamente limitada pelos processos de transmissão dos textos, não apenas quantitativamente, mas também, e sobretudo, pela determinação das modalidades de discurso dignas de terem sido postas em escrito. Vejamos um exemplo da problemática da metáfora viva em uma língua morta, analisado por Françoise Létoublon, em um artigo que insiste em evidenciar o caráter histórico

Sólon), ou à tirania. O que pode ser uma estratégia discursiva de um poema em que a ambiguidade e a polissemia seriam cuidadosamente trabalhados com fins retóricos (cf. Adkins, 1985, p. 24-125 e, para doulosýnè em particular, p. 118).

${ }^{9}$ Lloyd, 1996, p. 31-66; 2003, p. 8-10; Padel, 1992, p. 9-11 e 33-40 (p. 34 para a citação). 
e antropológico dos enunciados metafóricos. Quando se lê na Ilíada "o escudo de Nestor, cuja glória (kléos) alcança (híkę) o céu” (Hom. Il. 8, 192), de acordo com Létoublon:

pode-se crer em um emprego metafórico se o kléos for representado como uma abstração, à maneira da "glória" do herói francês clássico e se interpretamos o verbo como um verbo de movimento. Na verdade, o estudo do conjunto de empregos de cada um desses lexemas mostra que kléos é uma espécie de "rumor" ou de nuvem gloriosa concreta - espécie de auréola sonora? - e que o verbo significa, primeiro, o contato (Létoublon, 1989, p. 215).

Ou seja, no enunciado homérico, só há metáfora para nós, modernos.

Neste sentido, o modelo semântico da intercompreensão metafórica proposto por Vincent Nyckees se mostra bastante interessante para a análise dos sentidos figurados na Grécia antiga. A partir da constatação da natureza essencialmente coletiva (social, histórica e cultural) das significações linguageiras, o autor propõe que os enunciados metafóricos podem ser discernidos segundo uma escala de inovação em relação a modelos analógicos preexistentes, de modo que a intercompreensão metafórica se funda em uma guia das interpretações a partir das atestações disponíveis, das configurações semânticas em circulação entre os falantes de uma língua. Quer dizer que o desvio semântico dos enunciados metafóricos não implica nenhum desvio discursivo, nenhuma ruptura em relação à lógica linguageira. Indo das analogias inscritas na língua - as chamadas "metáforas mortas" que não constituem verdadeiras metáforas, mas expressões figuradas lexicalizadas - até as metáforas cuja radicalidade ameaça a compreensão dos interlocutores, o desvio de ordem semântica se relativiza em graus de metaforicidade (cf. Nyckees, 2000 e 2008).

Ainda que, para o helenista, a questão de determinar se uma expressão figurada constitui uma verdadeira metáfora ou uma analogia cristalizada na língua permaneça em muitos casos sem solução, a vantagem de tal modelo reside em fundamentar a análise no exame de ocorrências concretas, e, portanto, em uma prática amplamente adotada nos comentários filológicos aos textos antigos: a busca de paralelos. Por este caminho, evitamos as armadilhas das projeções de representações contemporâneas sobre as antigas. Tais armadilhas me parecem particularmente presentes na abordagem da linguística cognitiva. Não se trata, absolutamente, de negar a enorme importância das contribuições de Lakoff e Johnson para o estudo dos enunciados metafóricos, sobretudo ao insistirem na ancoragem somática do pensamento, no caráter prototípico das categorias, e na banalidade dos movimentos analógicos nos processos de significação, demonstrando que as metáforas não são um apanágio dos discursos considerados "literários". Na verdade, não se trata nem mesmo de refutar as propostas desses autores, mas, sim, de afirmar que teorias e métodos não são credos, são ferramentas, e sua adoção depende de serem mais ou menos adequados aos objetos estudados. Ainda que, em diversas passagens de Metaphors we live by, Lakoff e Johnson remetam aos fundamentos culturais das "metáforas conceituais" (1980, p. 6, 23-25 e 68), suas análises dão muito pouco espaço às dimensões antropológicas e históricas dos processos de significação, à diversidade das categorias que estruturam as metáforas conceituais. Com isso, 
a abordagem cognitiva acaba por apresentar uma tendência de universalizar os movimentos analógicos e, quando aplicada ao estudo de textos gregos antigos, acaba por nos induzir à projeção de nossas próprias categorias sobre as categorias dos textos estudados. Indução essa que talvez resulte menos da teoria cognitiva em si que do lugar de autoridade que a antiguidade grega ocupa no imaginário ocidental contemporâneo. Pois a frequentação dos textos antigos - e, portanto, a inclusão, a tradução e a reelaboração das analogias antigas nas memórias discursivas modernas - retomando, a frequentação dos textos antigos é uma das práticas fundamentais para a ilusão de continuidade de que depende a eleição da antiguidade greco-romana como mito de fundação da cultura ocidental.

\section{UM CORPO CÍvico? SigNIFICADOS DE SÔMA}

A tópica da cidade sofrente ilustra muito bem este tipo de armadilha. À primeira vista, tal concepção parece fazer referência à assimilação da cidade a um corpo, por intermédio das expressões "corpo cívico" ou "corpo social", que nos são tão familiares. Assim, Roger Brock, em um livro aliás extremamente rico, analisa as metáforas políticas na Grécia antiga a partir do modelo das metáforas conceituais de Lakoff e Johnson e intitula o capítulo dedicado à figura da cidade sofrente "The Body Politic" (Brock, 2013, p. 69-82). Além disso, e sintomaticamente, na introdução de seu estudo, Brock afirma: "a imagética política é parte do legado grego à cultura ocidental" (idem, xiii, n. 13).

No entanto, um breve exame dos empregos de sôma mostra quão ilusória é esta impressão de continuidade preservada em um legado. Em grego antigo, sôma remete à materialidade da pessoa e, como insiste Domenico Musti, mesmo nas passagens em que o vocábulo costuma ser traduzido por "pessoa" ou "personalidade" o aspecto físico permanece implicado. ${ }^{10}$ Porém, este suporte material do vivente que é o sôma não é concebido como um organismo, um conjunto articulado de partes cujas respectivas funções asseguram o funcionamento do todo (cf. Ioannidi, 1983; Grmek, 1994, p. 43). Sim, para alguns physiológoi e iatroí, sôma é um composto heterogêneo de partes e matérias que se integram continuamente em uma rede de forças múltiplas. Sim, os tratados hipocráticos mencionam partes, estruturas (skhếmata) e lugares (tópoi) que participam ativamente dos processos fisiológicos, notadamente no deslocamento dos fluidos. Desse modo, Robert Joly (1966, p. 75-81 e 163-167) descreve a "medicina" grega antiga como uma "física de recipientes". E B. Gundert, após passar em revista diversas passagens do Corpus hipocrático em que são mencionadas partes e estruturas do corpo, conclui:

Quando, ocasionalmente, a relação entre parte e processo é caracterizada em termos causais, é sempre uma relação de consequência - por exemplo "Nós falamos a partir do pulmão,

\footnotetext{
${ }^{10}$ Musti, 1993. O significado de sôma como suporte material do vivente contrasta, em parte, com o uso homérico, em que o vocábulo remete ao corpo morto desprovido dos cuidados fúnebres, distinguindo-se assim de nékyys/nekerós, “cadáver”; cf. Holmes, 2010, p. 32-37.
} 
porque é oco e tem uma flauta ligada a ele" (Morb. 4, 56); "a partir de lá [da medula espinhal] estendem-se passagens, de modo que o fluido possa viajar tanto para lá quanto a partir de lá” (Genit. 1) nunca de finalidade ou propósito. Partes podem executar papeis específicos por terem determinadas estruturas; jamais há sequer um indício de que as partes tenham determinadas estruturas com o fim de desempenhar determinados papeis (Gundert, 1992, p. 465).

Assim, dado que para os gregos antigos a unidade do sôma é o resultado de uma mistura sempre em movimento (e portanto perecível), as relações entre seus elementos constituintes, em geral invisíveis, não se definem como funcionais e/ou hierárquicas. Para citar um último exemplo do Corpus hipocrático, o autor do tratado Do regime afirma: "o corpo dos indivíduos (sôma) nunca é o mesmo, nem por natureza nem por força, pois ele se dissolve (diakrinetal) em tudo e se mistura (symmísgetal) com tudo" (De diet. 1, 28). ${ }^{11} \mathrm{O}$ corpo grego antigo não é um organismo, pelo menos não antes de Aristóteles; mas em nossas concepções modernas de corpo, a noção de organismo é fundamental. A diferença, por ser sutil, não deixa de ser importante: um organismo é composto por órgãos, ou seja, estruturas que se definem pela função que exercem.

Além disso, nos discursos atrelados a um contexto cívico, sôma designa a vida que o cidadão põe em risco quando vai lutar na guerra em nome da cidade, ou quando ele apresenta sua defesa em um processo capital nos tribunais, bem como o engajamento pessoal em uma liturgia, da qual ele participa ativamente, oferecendo não apenas seus bens e dinheiro, mas sua presença no local: em sua materialidade, o corpo se apresenta como recurso e como vitalidade - remetendo às duas acepções de bios na língua grega, "vida" e "víveres". ${ }^{12} \mathrm{Com}$ efeito, tendo em vista que o conjunto dos cidadãos já é uma das principais acepções do vocábulo pólis, podemos supor que a imagem de um "corpo cívico" - que por assim dizer vem reintroduzir o sentimento de concretude na noção abstrata de sociedade civil, noção esta ausente na antiguidade - não tinha razão de ser na Grécia antiga.

A que se assimila, então, a cidade na tópica discursiva de que nos ocupamos aqui? A resposta é bem mais simples do que se poderia esperar: não a um corpo, mas a uma pessoa. O emprego metafórico de hélkos, ferida, implica uma personificação da pólis. Comprova-o o

\footnotetext{
${ }_{11}$ Para esta concepção do corpo, cf. Holmes, 2010, p. 99-108, que além dessa passagem do corpus hipocrático, cita fragmentos pré-socráticos, como Empédocles (Diels-Kranz F 31 B 8 e 20) e Anaxágoras (Diels-Kranz F 59 B 17).

${ }^{12}$ Cf. Loraux, 1997, p. 225-226, que cita, para sôma como a vida que os atenienses oferecem à sua cidade, Tucídides 2, 24, 4; 2, 43, 2; 2, 64, 3; e 1, 70, 6; para a vida em risco em um processo capital: Andoc. De Myst. 4, 5, 123; e Lys. De caede Erat. 50. Nesses dois últimos casos, a ameaça concerne tanto aos sómata dos acusados quanto a suas fortunas (khrémata), do mesmo modo que, nos discursos judiciários em que se evocam as participações nas liturgias, são os bens e os corpos (as presenças) que são postos a serviço da cidade (cf. Wilson, 2000, p. 135-136). Em seu estudo sobre o corpo na historiografia de Tucídides, Loraux também constata a ausência do corpo como figura da coletividade (1997, p. 239 e 244-245), imagem mais romana do que grega (ver, p. ex. T. Liv. 2, 32,9).
} 
emprego do adjetivo polyératon, "muito amada", ou "eroticamente muito desejada", à cidade, ásty, no verso 21 do fragmento de Sólon. Com efeito, a pólis é frequentemente personificada nos textos ligados a contextos cívicos do período clássico, quer nos exemplos da tópica erótica estudados por Yatromanolakis (2005); quer nos textos das orações fúnebres públicas, analisados por Loraux (1993); ou ainda, como observa Hansen (2001, p. 31-54, 79-124 e, em particular, 85-97), nos decretos oficiais em que é a pólis que vota, que faz guerra, organiza uma festa etc. Além disso, o célebre triângulo hipocrático - o médico, o doente e a doença - parece deixar claro que os iatroí gregos não cuidavam de corpos, mas de pessoas. Por fim, estas observações acerca da figura da cidade sofrente na Grécia podem explicar uma questão que surpreende Brock em seu estudo: a ausência de detalhes anatômicos nos empregos da figura da cidade doente (Brock, 2013, p. 71). E o fato de as relações entre as partes do corpo não terem lugar nos empregos desta figura me parece corroborar a ausência da própria noção de "corpo cívico", que, como visto, implicaria conceber seus componentes de acordo com seus papeis. Isto posto, retornemos às ocorrências da figura da cidade ferida.

\section{A CIDADE FERIDA: PRAgmátiCa DE UMA METÁFORA}

Como paralelo do emprego metafórico de hélkos, os comentadores do verso $17 \mathrm{da}$ Eunomía de Sólon frequentemente citam três outras passagens: o fragmento 13 West (8) de Arquíloco, os versos 1134-1135 dos Theognidea e uma passagem da Pítica 4 de Píndaro. Eis os versos de Arquíloco:

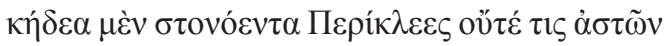

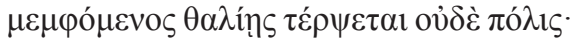

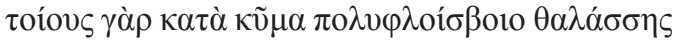

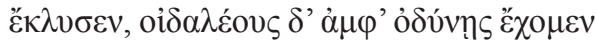

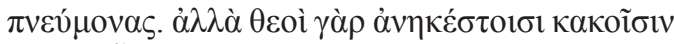

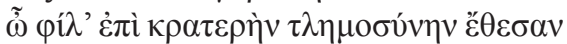

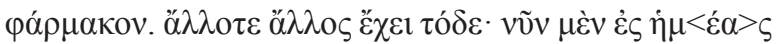

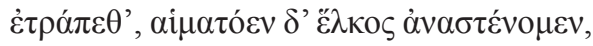

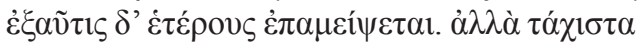

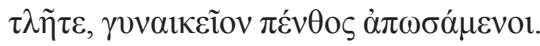

não é, Péricles, deconsiderando o nosso pesar gemente, que um cidadão vai se deleitar com a festa - nem a cidade:

pois aqueles que a onda do mar de grave estrondo submergiu eram tais que pela dor temos inchados

os pulmões. Mas os deuses, contra males incuráveis, meu caro, prescrevem a vigorosa persistência

como remédio. Cada um, na sua vez, tem isto: agora contra nós se voltou, e gememos sobre a ferida sangrenta;

n'outra vez, a outros caberá. Mas, rapidíssimo, persistam e afastem esse luto de mulher. 
Esta proposta de tradução deve muito à análise detalhada de Deborah Steiner (2012). Seguindo Ewin Bowie (1986), D. Steiner propõe que os versos elegíacos de Arquíloco não se vinculam a um contexto funerário, mas sim à ocasião de um simpósio. Concordando com os comentários de Kamerbeek (1961, p. 1-3) aos versos 1 e 2, interpreto as negações em correlação outé...oudé como modificadores do particípio memphómenos, traduzido aqui por "desconsiderando", e não do verbo térpsetai, "vai se deleitar". Quer dizer que a cidade não cessa suas festividades por causa do naufrágio que matou homens valorosos, pelo menos ao próprio Arquíloco, já que segundo o testemunho de Plutarco (Quomodo aud. poet. 33ab), o cunhado de Arquíloco estava entre os navegantes. De modo que os que gemem sobre a ferida sangrenta no verso 8 não são todos os cidadãos, nem a cidade, mas Arquíloco e seus companheiros de banquete (cf. 6, "contra nós"). ${ }^{13} \mathrm{O}$ que quer dizer que, cronologicamente anterior aos versos de Sólon, a elegia de Arquíloco inaugura a ferida metafórica em um contexto comunitário, mas não a figura da cidade ferida.

Por outro lado, a ferida do verso atribuído a Teógnis de Mégara parece ter uma referência política mais marcada, que caracteriza o contexto geral dos dísticos elegíacos transmitidos até nós sob o nome deste poeta, contexto de conflitos entre uma aristocracia fundiária tradicional e uma aristocracia enriquecida com o advento da moeda. ${ }^{14} \mathrm{O}$ poeta de Mégara, pertencente à aristocracia tradicional, dirige o seguinte apelo a seu amigo Cirno:

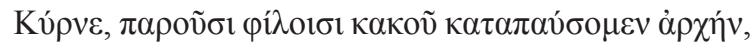

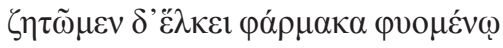

Cirno, com os amigos que estão aqui, ponhamos um fim ao início do mal e busquemos um remédio à ferida crescente.

(Theog. 1134-1135)

Por fim, restam os versos da Pítica 4, que celebra a vitória do rei de Cirene, Arcesilau IV, na corrida de carros. Ao fazer um apelo pelo retorno de Damofilo, exilado de Cirene por ter conspirado contra o rei, Píndaro se dirige a Arcesilau:

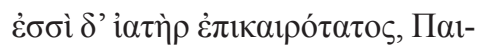

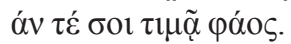

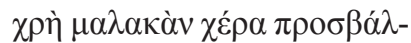

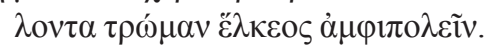

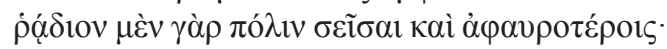

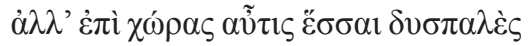

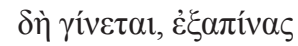

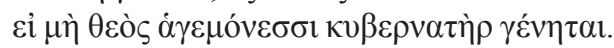

\footnotetext{
${ }^{13}$ Sobre o fr. 13 West de Arquíloco, ver igualmente a análise de Adkins, 1985, p. 35-44.

${ }^{14}$ Acerca do contexto geral dos conflitos políticos em Mégara de que tratam os Theognidea, bem como sobre a inserção destes poemas em um âmbito pan-helênico, ver Nagy, 1985.
} 


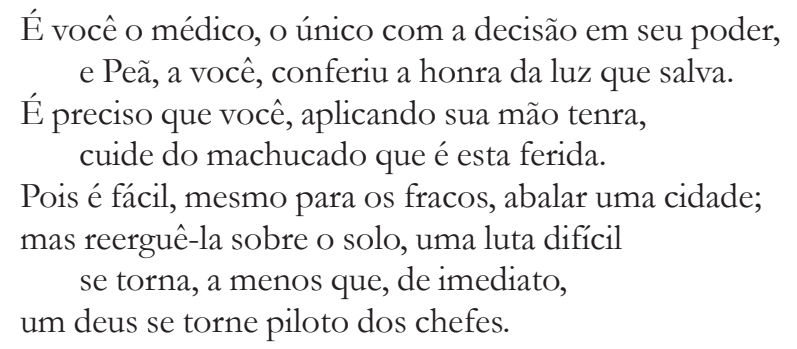

(Pind. Pyth. 4, 270-274)

O emprego metafórico de hélkos, "ferida" (aqui como genitivo apositivo de tróma, "machucado"), ganha neste passo em especificidade e complexidade. Com efeito, trata-se de um exemplo do encadeamento de imagens característico de Píndaro: ${ }^{15}$ a ferida retoma a metáfora do carvalho derrubado com a qual o poeta havia introduzido o apelo por Damofilo, ${ }^{16}$ dando-lhe uma outra direção. As duas metáforas se associam por meio da imagem de um "golpe". A este propósito, vale lembrar que a imagem do carvalho derrubado é empregada na Iliada para descrever, por meio de um símile, a queda de Heitor atingido por Ájax (Hom. Il. 14, 414-418). Assim, na Pítica 4, tanto a metáfora do carvalho, representando a expulsão de Damofilo, quanto a da ferida, remetendo à ausência de Damofilo em Cirene, constituem reelaborações da tópica da guerra aplicadas a um conflito político interno. A ação da lâmina cortante sobre a árvore que, a partir de então, se encontra entre os muros de outra cidade se transforma, assim, em ferida. ${ }^{17}$

Ora, em todas essas passagens a ferida é evocada para falar não apenas do mal de que se sofre, mas sobretudo da busca de um remédio. Os próprios poetas participam desta busca: o dos Theognidea convida Cirno a buscar um phármakon, Arquíloco lembra a Péricles a prescrição divina, a "vigorosa persistência" (6). Ainda, se seguimos a leitura de D. Steiner (2012), o poeta incita seus companheiros a se resignarem, deixar o pesar caber a outros e a se deleitar no simpósio, ou seja, a tomar outros remédios muito célebres na Grécia antiga por trazerem o esquecimento das tristezas: a poesia e o vinho. Já Píndaro intercede junto ao único que tem a capacidade de curar a ferida de Cirene, dirigindo-se ao rei como "iatrós". Por fim, os versos de Sólon dão um diagnóstico dos males da cidade: o desrespeito à augusta sede da justiça. Este engajamento dos poetas em remediar as feridas metafóricas sem dúvida remete à posição de autoridade que ocupavam nas póleis gregas antigas. De fato, o poeta não precisa ser também um legislador, como foi Sólon, para que sua fala adquira a autoridade ética de um "campeão da justiça", para usar a expressão de Gregory Nagy (1985, p. 36-41), ou um "mestre de verdades", adaptando a fórmula de Marcel Detienne (2006 passim). A menção dessas feridas metafóricas parece indissociável da capacidade que a própria poesia tem de tomar parte no tratamento.

\footnotetext{
${ }^{15}$ Sobre o encadeamento de imagens na poesia de Píndaro, ver Péron, 1970, p. 12-14.

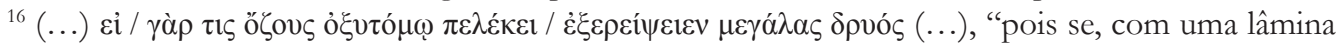
cortante, derrubam-se os ramos de um grande carvalho...”; Pind. Pyth. 4, 263-264.

${ }^{17}$ Para comentários mais detalhados aos versos 263-274 da Pítica 4, ver Braswell, 1988, p. 360-376.
} 
Portanto, em termos mais abstratos, a metáfora da ferida faria referência não somente à presença de um distúrbio, mas sobretudo à necessidade da intervenção de alguém dotado de um saber que possibilite dar um termo a esse distúrbio, seja pela ação do próprio poeta ou pela ação de seus destinatários. Neste sentido, os modificadores do vocábulo hélkeos nas ocorrências citadas enfatizariam a gravidade da ferida e, consequentemente, a necessidade de um saber especial para curá-la: a ferida é áphykton, "inevitável”, em Sólon; haimatóen, "sangrenta”, em Arquíloco; phyoménon, "crescente", nos Theognidea; e o mesmo efeito intensificador é obtido no emprego pindárico, em que hélkos ocorre em um genitivo apositivo que amplifica a gravidade da tróma, do machucado sobre o qual Arcesilau deve aplicar sua mão. Ainda neste mesmo sentido, é significativo que desde Homero os aedos pertençam à categoria dos demiurgos, tal como os carpinteiros, os arautos, os adivinhos e notadamente os iatroí, os "médicos"; e, ainda que os próprios poetas pareçam não ter feito referência à sua habilidade em termos de tékhnè, uma arte prática, mas em termos de sophía, de sabedoria, as metáforas artesanais são muito frequentes nos versos que descrevem a atividade poética. ${ }^{18}$ Deste modo, o savoir-faire dos poetas, por meio da enunciação mesma dos poemas, participa diretamente da busca de tratamento no caso de Arquíloco, de Sólon e dos Theognidea, enquanto Píndaro põe sua sabedoria a serviço do rei-médico Arcesilau. A figura da cidade ferida colocaria, assim, em evidência o poder que os poetas têm, pela própria eficácia de seus versos, de se engajar na busca da solução dos mal-estares comunitários. A figura remete, deste modo, senão à autoridade efetiva da poesia na pólis, ao menos às reivindicações dos poetas por uma voz de autoridade.

\section{REFERÊNCIAS ${ }^{19}$}

ADKINS, Arthur W. H. Poetic Craft in the Early Greek Elegists. Chicago / London: University of Chicago Press, 1985.

BRASWELL, Bruce Karl. A Commentary on the Fourth Pythian Ode of Pindar. Berlin/ Boston: De Gruyter, 1988.

BOWIE, Ewen. "Early Greek Elegy, Symposium and Public Festival". The Journal of Hellenic Studies, vol. 106, p. 13-35, 1986.

BROCK, Roger. Greek Political Imagery from Homer to Aristotle. London: Blackwell, 2013.

DETIENNE, Marcel. Les maîtres de la vérité dans la Grèce archä̈que. Paris: Le livre de poche, 2006.

FORD, Andrew. The Origins of Criticism. Literary Culture and Poetic Theory in Classical Greece. Princeton/Oxford: Princeton University Press, 2002.

\footnotetext{
${ }^{18}$ Cf., p.ex., Od. 17, 383-385. Sobre o emprego de metáforas artesanais com referência à atividade poética, ver Gentili, 1988, p. 4-5, e Ford, 2002, p. 113-130.

${ }^{19}$ Salvo menção contrária, as edições dos textos antigos consultadas foram as constantes do Thesaurus Linguae Graeca (http://stephanus.tlg.uci.edu/index.php).
} 
GENTILI, Bruno \& PRATO, Carlo. Pars I Poetarum elegiacorum testimonia et fragmenta. Berlin/ Boston: B. G. Teubner, 1988.

GENTILI, Bruno. Poetry and its Public in Ancient Greece. From Homer to the fifth century. Baltimore / London: The Johns Hopkins University Press, 1988.

GRMEK, Mirko. "La pratique médicale”. In: Hippocrate. De l'art médical. Paris: Le livre de poche, 1994, p. 40-59.

VAN GRONINGEN, Bernard Abraham. Théognis. Le premier livre édité avec un commentaire. Amsterdam: N.V. Noord-Hollandsche Uitgevers Maatschappij, 1966.

GUNDERT, Beate. "Parts and their roles in Hippocratic medicine". Isis, vol. 83, n. 3, p. 453-465, 1992.

HANSEN, Mogens Herman. Polis et cité-État. Un concept antique et son équivalent moderne. Paris: Les Belles Lettres, 2001.

HOLMES, Brooke. The Symptom and the Subject. The emergency of the Physical Body in Ancient Greece. Princeton / Oxford: Princeton University Press, 2010.

IOANNIDI, Hélène. "Les notions de partie du corps et d'organe". In: Formes de Pensée dans la Collection hippocratique, 21-26 septembre 1998, Lausanne. Actes du 4e Colloque international hippocratique. Génève: Droz, 1983, p. 327-330.

IRWIN, Elizabeth. Solon and Early Greek Poetry. The Politics of Exhortation. Cambridge: Cambridge University Press, 2005.

JAEGER, Werner. Paideia. La formation de l'homme grec. Paris: Gallimard, 1988.

JOLY, Robert. Le niveau de la science hippocratique. Paris: Les Belles Lettres, 1969.

KAMERBEEK, Jan Coenraad. "Archilochea”. Mnemosyne, vol. 14, p. 1-15, 1961.

LAKOFF, George \& JOHNSON, Mark. Metaphors we live by. Chicago / London: The University of Chicago Press, 1980.

LÉTOUBLON, Françoise. "La métaphore vive dans les langues mortes". Recherches sur la philosophie et le langage, n. 9, p. 212-238, 1988.

LLOYD, Geoffrey Ernest Richard. Pour en finir avec les mentalités. Paris: La découverte (Poche), 1996.

LLOYD, Geoffrey Ernest Richard. In the Grip of Disease. Studies in Greek Imagination. Oxford: Oxford University Press, 2003.

LORAUX, Nicole. L'Invention d'Athènes. Histoire de l'oraison funèbre dans la « cité classique ». Paris: Payot-Rivages, 1993.

LORAUX, Nicole. "Un absent de l'Histoire ? Le corps dans l'historiographie thucydidéenne". Mètis, vol.12, p. 223-267, 1997. 
MUSTI, Domenico. "Soma in Tucidide e in Gorgia". In: Tradizione e innovazione nella cultura greca da Homero all' età ellenistica: Scritti in onore di B. Gentili. R. Prestagostini: Roma, 1993, p. 853-864.

NAGY, Gregory. “Theognis and Megara : A Poet's Vision of His City”. In: FIGUEIRA \& G. NAGY (ed.). Theognis of Megara. Poetry and the Polis. Baltimore /London: The Johns Hopkins University Press, 1985, p. 22-81.

NYCKEES, Vincent. La sémantique. Paris: Belin, 1998.

NYCKEES, Vincent. “Quelle est la langue des métaphores?”. Cahiers de Praxématique, n. 35, p. 115-139, 2000.

NYCKEES, Vincent. 'Rien n'est sans raison: les bases d'une théorie continuiste de l'évolution sémantique”. In: CANDEL \& GAUDIN. Aspects diachroniques du vocabulaire. Mont-SaintAignan: Publications des Universités de Rouen et du Havre, 2006, p. 15-88.

NYCKEES, Vincent. "Le sens figuré en langue et en discours : les sources linguistiques de l'énonciation métaphorique". In: SAKAI \& STRUVE. Regards sur la métaphore, entre Orient et Occident. Arles: Éditions Philippe Picquer, 2008, p. 13-29.

NOUSSIA, Maria. Solone. Frammenti dell'opera poetica. Premessa di H. Maehler, introduzione e commento di M. Noussia, traduzione di M. Fantuzzi. Milano: Biblioteca Universale Rizzoli, 2001.

PADEL, Ruth. In and out of the Mind. Greek Images of the Tragic Self. Princeton: Princeton University Press, 1992.

PÉRON, Jacques. Les images maritimes de Pindare. Paris: Klincksieck, 1974.

STEINER, Deborah. "Drowning Sorrows: Archilocus fr. 13W in its Performance Context". Greek, Roman, and Byzantine Studies, v. 52, p. 21-56, 2012.

TRÉDÉ, Monique. Kairos. L'à-propos et l'occasion. Le mot et la notion, d'Homère à la fin du IVe siècle avant J.-C. Paris: Klincksieck, 1992.

WEST, Martin. Iambi et elegi graeci ante Alexandrum cantati. Oxford: Oxford Univeristy Press, 1998.

WILSON, Peter. The Athenian Institution of Khoregia. The Chorus, the City and the Stage. Cambridge: Cambridge University Press, 2000.

YATROMANOLAKIS, Yorgis. "Poleos Erastes: the Greek city as the beloved". In: STAFFORD \& HERRIN. Personification in the Greek World: From Antiquity to Byzantium. Aldershot: Ashgate, 2005, p. 267-283.

Recebido em 30 de julho de 2017 Aprovado em 10 de agosto de 2017 